\title{
Dois verbos e duas medidas: comparando tratamentos lexicográficos de verbi procomplementari e phrasal verbs em dicionários bilíngues
}

\section{Two verbs, two differing measures: comparing lexicographical treatment of verbi procomplementari and phrasal verbs in bilingual dictionaries}

\author{
Roseli Dornelles dos Santos \\ Paola Giustina Baccin**
}

Resumo: 0 objetivo deste trabalho é a caracterização dos verbi procomplementari (VPs) da língua italiana e a análise do tratamento lexicográfico recebido por dois VPs em três dicionários bilíngues italiano-português. Comparamos os VPs com os phrasalverbs (PhVs) da língua inglesa em relação às suas características e, sobretudo, ao tratamento lexicográfico recebido por dois $\mathrm{PhVs}$ em três dicionários bilíngues inglês-português. Além disso, discutimos a função e tipologia de dicionários bilíngues, especialmente os de língua italiana, e a relação de escolhas lexicográficas distintas concernentes às duas tipologias verbais aqui estudadas.

Palavras-chave: Verbi procomplementari; Phrasal verbs; lexicografia bilíngue; lexicografia pedagógica.

* Doutoranda do Programa de Língua, literatura e cultura italianas da FFLCH - USP. rdsantos@usp.br

"* Docente de Língua Italiana da FFLCH - USP. pbaccin@usp.br 
SANTOS, R. D. DOS; BACCIN, P. G. - Dois verbos e duas medidas: comparando tratamentos lexicográficos de verbi procomplementari e phrasal verbs em dicionários bilíngues

Abstract: The objective of this work is the characterization of verbi procomplementari (VPs) of the Italian language and the analysis of the lexicographical treatment received by two VPs in three Italian-Portuguese bilingual dictionaries. We compared the VPs to phrasal verbs (PhVs) of the English language in relation to their features and, above all, to the lexicographical treatment received by two PhVs in three English-Portuguese bilingual dictionaries. Moreover, we discussed the role and typology of bilingual dictionaries, especially the ones in the Italian language, and the relationship of different lexicographical choices concerning both verbal typologies studied here.

Keywords: Verbi procomplementari; Phrasal verbs; Bilingual lexicography; Pedagogical lexicography.

\section{Introdução e histórico}

O objetivo deste trabalho é a caracterização dos verbi procomplementari (VPs) da língua italiana e a análise do tratamento lexicográfico recebido por dois VPs em três dicionários bilíngues italianoportuguês. Do mesmo modo, comparamos os VPs com os phrasal verbs (PhVs) da língua inglesa em relação às suas características e, sobretudo, em relação ao tratamento lexicográfico recebido por dois $\mathrm{PhVs}$ em três dicionários bilíngues inglês-português. Discutimos a função e a tipologia de dicionários bilíngues, especialmente os de língua italiana, e a relação de escolhas lexicográficas distintas concernentes às duas tipologias verbais aqui estudadas, avaliando sobre como tais escolhas se refletem no uso dos dicionários bilíngues por parte dos aprendizes e apresentando algumas propostas. 
SANTOS, R. D. DOS; BACCIN, P. G. - Dois verbos e duas medidas: comparando tratamentos lexicográficos de verbi procomplementari e phrasal verbs em dicionários bilíngues

Os VPs da língua italiana são antigos, mas ainda pouco estudados. 0 verbo andarsene [ir embora] ${ }^{1}$, com datação de 1294 (segundo DE MAURO 2000), é um bom exemplo de um VP dos mais frequentes, antigos e importantes.

Os VPs se enquadram dentro da categoria de verbi sintagmatici ${ }^{2}$ (VS) da língua italiana, categoria esta que vem sendo cada vez mais estudada por linguistas italianos e de outras nacionalidades.

Raffaele Simone parece ter sido o primeiro a se debruçar e refletir sobre essa tipologia verbal. Em 1996, publica o artigo pioneiro Esistonoverbi sintagmatici in italiano?, no qual analisa e caracteriza o funcionamento e as subcategorias de tais verbos. Nesse artigo, Simone aborda o fenômeno, na língua italiana, da presença de verbos comparáveis aos PhVs ingleses. Ao descrever essa tipologia verbal, ele os denomina de verbi sintagmatici e divide-os em três subcategorias: a) verbos pronominais simples, como vederci [enxergar] e starci [topar], formados por um único pronome; b) verbos pronominais múltiplos, como prendersela [zangar-se] e farsela [ter um caso/estar envolvido com alguém], formados por dois pronomes e c) verbos sintagmático-pronominais, como farsi sotto [empenhar-se] e farsela addosso[ borrar-se], formados por um verbo, mais uma ou duas partículas pronominais e um advérbio.

Posteriormente, Tullio De Mauro (2000), no Dizionario della lingua italiana per il terzo millennio, da Editora Paravia, na seção Avvertenze per la consultazione: lemmatizzazione e criteri generali, denomina as duas primeiras subcategorias verbais enunciadas por Simone $^{3}$ de verbi procomplementari:

\footnotetext{
${ }^{1}$ As traduções entre colchetes se referem às acepções mais frequentes dos VPs. Todas as traduções são nossas.

2 Preferimos manter a nomenclatura italiana por ainda não termos encontrado uma designação correspondente em artigos escritos em língua portuguesa.

${ }^{3}$ Embora trate dos verbos conjugados com uma ou duas partículas pronominais, De Mauro não menciona o trabalho de Simone.
} 
SANTOS, R. D. DOS; BACCIN, P. G. - Dois verbos e duas medidas: comparando tratamentos lexicográficos de verbi procomplementari e phrasal verbs em dicionários bilíngues

Aparecem como entrada alguns verbos procomplementares dotados de um significado próprio que não pode ser atribuído ao verbo principal, ou com um significado muito cristalizado: avercela [estar zangado], cavarsela [arranjar-se], fregarsene [não ligar]. Possuem qualificação gramatical ' $v$. procompl.' marca de uso e indicação da primeira pessoa" (quando necessário). (DE MAURO 2000: XXXIV) ${ }^{4}$

São essas duas primeiras subcategorias verbais descritas por Simone, isto é, os verbos conjugados com uma ou duas partículas pronominais, o objeto de nossa pesquisa. Por não abordarmos a terceira subcategoria (verbos sintagmático-pronominais) apontada por Simone, adotaremos a nomenclatura de De Mauro, verbi procomplementari.

Simone afirma que o termo que usou para designar esses verbos é um decalque do inglês phrasal verbs, já que formam uma categoria muito próxima destes, além de ser possível adotar, para a identificação dos verbi sintagmatici, os mesmos critérios que são usados para a identificação dos PhVs.

[...] os VS [verbi sintagmatici] têm uma coesão e uma coerência particulares, não podendo ser reduzidos à soma de seus constituintes. Além disso, situam-se em uma zona pouco clara entre a morfologia e o léxico, e não é possível formular uma regra morfológica para gerá-los. ${ }^{5}$ (SIMONE 1996: 49)

Apesar das caraterísticas semelhantes, os verbi sintagmatici da língua italiana são muito menos numerosos do que os de língua inglesa e os de língua

\footnotetext{
${ }^{4}$ Figurano a lemma alcuni verbi procomplementari dotati di un proprio significato non riconducibile al verbo principale o molto cristallizzato: avercela, cavarsela, fregarsene. Hanno qualifica grammaticale “v.procompl.", marca d'uso e l'indicazione della prima persona (quando necessaria).

${ }^{5}$ [...] i VS hanno una coesione e una coerenza particolari, e non possono quindi essere ridotti a pure sommatorie di costituenti. In aggiunta, si collocano in una zona grigia tra morfologia e lessico: non pare che si possa formulare una regola morfologica (ad esempio di formazione di parola) per generarli.
} 
SANTOS, R. D. DOS; BACCIN, P. G. - Dois verbos e duas medidas: comparando tratamentos lexicográficos de verbi procomplementari e phrasal verbs em dicionários bilíngues

alemã, segundo Simone. Mesmo ocorrendo em número menor na língua italiana, no dicionário De Mauro são elencados pelo menos 131 VPs, e esse número pode ser ainda maior. Tal fato pode ter sido a razão para o pouco estudo sobre eles até o trabalho de Simone. A partir dele, então, a pesquisa sobre as três subcategorias aumentou em número, variedade e dispersão geográfica. Além de estudos, principalmente na Itália, sobre as questões de dessemantização dos clíticos, gramaticalização e lexicalização em relação aos verbi procomplementari, ocorreram também pesquisas relacionadas à sua presença e tratamento em obras lexicográficas monolíngues e bilíngues. Além de Simone e De Mauro, Andrea Viviani (2006) estudou os VPs em relação à sua formação, ou seja, uma base verbal unida a um ou mais elementos pronominais com valor semântico distante do verbo base, em relação à presença e análise de tais verbos em gramáticas italianas e por fim, em relação à presença e apresentação dos VPs em dicionários bilíngues inglês-italiano.

Em sua pesquisa, Viviani (2006: 255) comenta a semelhança na dificuldade de aprendizado entre os PhVs e os VPspor parte dos discentes. Isto ocorre porque, embora os PhVs ingleses não apresentem partículas pronominais como os clíticos italianos, a variação da posição das partes componentes e o significado sintagmático que as duas categorias verbais podem apresentar pode gerar dificuldades de aprendizado e uso.

Segundo o Cambridge Academic Content Dictionary, um phrasal verb é:

Uma combinação de um verbo com um advérbio ou de um verbo com uma preposição, ou ambos, na qual a combinação tem um significado diferente do significado das palavras consideradas separadamente. ${ }^{6}$

\footnotetext{
${ }^{6}$ http://dictionary.cambridge.org/us/dictionary/english/phrasal-verb?a=british $A$ combination of a verb and an adverb or $a$ verb and a preposition, or both, in which the combination has a meaning different from the meaning of the words consideredseparately. Acesso em: 11 set. 2015.
} 
SANTOS, R. D. DOS; BACCIN, P. G. - Dois verbos e duas medidas: comparando tratamentos lexicográficos de verbi procomplementari e phrasal verbs em dicionários bilíngues

Essa definição vem ao encontro tanto da definição dada por DE MAURO aos VPs quanto da definição e caracterização dada por Simone aos verbi sintagmatici. Considerando a similaridade entre essas duas categorias verbais, analisamos e discutimos a presença e o tratamento lexicográfico dos VPs e dos PhVs em dicionários bilíngues, especificamente os que envolvem o português brasileiro.Tratamos também sobre as funções e perfis dos dicionários e seus respectivos públicos-alvo, assim como refletimos sobre como os aprendizes usam os dicionários e, ao final, elaboramos algumas propostas.

\section{Dicionários, verbos e componentes lexicográficos}

Apresentamos, primeiramente, os dicionários e verbos pesquisados, seguidos dos resultados obtidos pela análise do tratamento lexicográfico dos VPs nos dicionários bilíngues italianos e pela análise dos PhVs nos dicionários bilíngues ingleses. A análise de apenas dois verbos de cada tipo é ilustrativa de um fato mais amplo que já observamos e pesquisamos.

\subsection{Verbos e dicionários analisados}

Avaliamos neste estudo especificamente a presença e o tratamento lexicográfico dado aos VPs volerci [ser necessário] e cavarsela[arranjar-se], o primeiro com marca de uso FO (fundamental) ${ }^{7}$ e o segundo com marca de uso

\footnotetext{
7 FO: fondamentale; tra $i$ lemmi principali, sono cosi marcati $i$ vocaboli di altissima frequenza, le cui occorrenze costituiscono circa il $90 \%$ delle occorrenze lessicali nell'insieme di tutti i testi scritti o discorsi parlati. [FU: fundamental; entre as entradas principais, são marcadas assim as palavras de altíssima frequência, cujas ocorrências constituem cerca de
} 
SANTOS, R. D. DOS; BACCIN, P. G. - Dois verbos e duas medidas: comparando tratamentos lexicográficos de verbi procomplementari e phrasal verbs em dicionários bilíngues

CO (comum) $)^{8}$, isto é, VPs de alta ocorrência e relativa opacidade semântica em três dicionários bilíngues italiano-português:

1. Dicionário Martins Fontes Italiano Português - Martins Fontes - Ivone C. Benedetti -2004.

2. Dicionário Escolar Italiano Michaelis -André Guilherme Polito Editora Melhoramentos - 2007.

3. Parola Chiave - Dizionario di italiano per brasiliani - Giunti \& Martins Fontes - Carlo Alberto Dastoli et al - 2007.

Os três dicionários acima foram escolhidos por estarem entre os mais recentes e os mais usados dicionários bilíngues de língua italiana que trabalham com a variante brasileira do português. Essa afirmação, entretanto, deriva apenas de nossa observação e da opinião de outros colegas professores, não tendo como base nenhum dado mercadológico. Os dicionários analisados apresentam características diferentes, que foram abordadas na dissertação de mestrado de Santos (2011).

Os PhVs analisados são give up [desistir] e get over[superar], que também figuram entre os mais frequentes da língua inglesa. Estes dois PhVs foram analisados em relação ao tratamento lexicográfico recebido nos seguintes dicionários bilíngues inglês-português:

90\% das ocorrências lexicais no conjunto de todos os textos escritos ou discursos orais.] http://dizionario.internazionale.it/avvertenze/6. Acesso em: 11 set. 2015.

${ }^{8} \mathrm{CO}$ : comune; sono cosi marcati $i$ vocaboli che sono usati e compresi indipendentemente dalla professione o mestiere che si esercita o dalla collocazione regionale e che sono generalmente noti a chiunque abbia un livello mediosuperiore di istruzione. [CO: comum; são assim marcadas as palavras usadas e compreendidas e geralmente conhecidas por qualquer pessoa que tenha um nível médio-superior de instrução, independentemente da profissão, do trabalho exercido e da região.] http://dizionario.internazionale.it/avvertenze/6. Acesso em: 11 set. 2015. 
SANTOS, R. D. DOS; BACCIN, P. G. - Dois verbos e duas medidas: comparando tratamentos lexicográficos de verbi procomplementari e phrasal verbs em dicionários bilíngues

a) Michaelis Dicionário Escolar Inglês e Português - Ivanete Tosi Araújo Silva et al. - Editora Melhoramentos - 2007.

b) Password English dictionary for speakers of Portuguese - Lionel Kenerman - Martins Fontes - 1998.

c) Longman Dicionário escolar inglês-português/português-inglês - Rita de Cássia Marinho Bueno de Abreu et al - Harlow - 2002.

Assim como os dicionários bilíngues do italiano, os dicionários bilíngues do inglês foram escolhidos pela sua representatividade (Michaelis), pela tentativa de analisar paralelismos entre dicionários das mesmas coleções (Michaelis e Password) e, finalmente, por analisar e comparar as escolhas lexicográficas adotadas em um dicionário bilíngue com recursos pedagógicos (Longman) ${ }^{9}$.

Tanto os VPs quantos PhVs foram analisados em relação aos seguintes componentes na microestrutura dos dicionários:

- Presença do verbo como entrada ou subentrada

- Presença de definição

- Presença de equivalentes

- Presença de exemplo(s)

- Presença de nota ou marca de uso

- Presença de indicação de categoria gramatical

- Indicação de conjugação

Os dicionários analisados seguem a tipologia abaixo:

\footnotetext{
9 Para mais informações sobre os dicionários bilíngues do inglês, ver HUMBLÉ, Philippe. Melhor do que muitos pensam. Quatro dicionários bilíngues português - inglês de uso escolar. Cadernos de Tradução, Florianópolis, v. 2, n. 18, pp. 253-273, set. 2008. ISSN 2175-7968. Disponível em: <https://periodicos.ufsc.br/index.php/traducao/article/view/6951/6459>. Acesso em: 11 set. 2015.
} 
SANTOS, R. D. DOS; BACCIN, P. G. - Dois verbos e duas medidas: comparando tratamentos lexicográficos de verbi procomplementari e phrasal verbs em dicionários bilíngues

\begin{tabular}{|c|c|c|c|}
\hline & Martins Fontes & Parola Chiave & Michaelis \\
\hline $\begin{array}{c}\mathrm{N}^{\circ} \text { de } \\
\text { Verbetes }\end{array}$ & 82000 & 20000 & 28000 \\
\hline $\begin{array}{c}\text { Objetivo do } \\
\text { dicionário }\end{array}$ & decodificação & decodificação & $\begin{array}{c}\text { decodificação e } \\
\text { codificação }\end{array}$ \\
\hline Público-alvo & $\begin{array}{c}\text { tradutores e } \\
\text { professores }\end{array}$ & estudantes & estudantes \\
\hline Sistema & semasiológico & semasiológico & semasiológico \\
\hline $\begin{array}{c}\text { Tipo de } \\
\text { dicionário }\end{array}$ & bilíngue & semibilíngue & bilíngue \\
\hline
\end{tabular}

1. Tabela: Tipologia de dicionários italiano-português

\begin{tabular}{|c|c|c|c|}
\hline $\begin{array}{c}\text { No de } \\
\text { Verbetes }\end{array}$ & não informado & não informado & 25000 \\
\hline $\begin{array}{c}\text { Objetivo } \\
\text { do } \\
\text { dicionário }\end{array}$ & decodificação & $\begin{array}{c}\text { decodificação e } \\
\text { codificação }\end{array}$ & $\begin{array}{c}\text { decodificação e } \\
\text { codificação }\end{array}$ \\
\hline $\begin{array}{c}\text { Público- } \\
\text { alvo }\end{array}$ & estudantes & estudantes & estudantes \\
\hline Sistema & semasiológico & semasiológico & semasiológico \\
\hline $\begin{array}{c}\text { Tipo de } \\
\text { dicionário }\end{array}$ & semibilíngue & bilíngue & bilíngue \\
\hline
\end{tabular}

2. Tabela: Tipologia de dicionários inglês-português

\subsection{Resultados:}

A análise dos verbetes nos dicionários italiano-português retornou os seguintes resultados: 
SANTOS, R. D. DOS; BACCIN, P. G. - Dois verbos e duas medidas: comparando tratamentos lexicográficos de verbi procomplementari e phrasal verbs em dicionários bilíngues

\begin{tabular}{|l|c|c|}
\multicolumn{1}{c}{ Martins Fontes } & volerci & cavarsela \\
\hline Entrada & - & - \\
\hline Subentrada & $\mathrm{X}$ & $\mathrm{X}$ \\
\hline Definição & - & - \\
\hline Equivalentes & $\mathrm{X}(8)$ & $\mathrm{X}(4)$ \\
\hline exemplo(s) & $\mathrm{X}(4)$ & $\mathrm{X}(1)$ \\
\hline Locuções & $\mathrm{X}(1)$ & $\mathrm{X}(1)$ \\
\hline nota/marca de uso & - & - \\
\hline categoria gramatical & - & $\mathrm{X}$ \\
\hline Conjugação & - & - \\
\hline
\end{tabular}

3. Tabela: Presença dos VPs pesquisados no dicionário Martins Fontes. O símbolo (X) indica a presença e o símbolo $(-)$ indica a ausência. 0 número entre parênteses indica a quantidade de cada item.

Neste dicionário, os VPs volerci e cavarsela são indicados pelo símbolo $(\square)$, no interior dos verbetes relativos aos verbos volere [querer] e cavare [tirar], respectivamente.

No dicionário não há indicação do significado dos símbolos usados, apesar de haver, como componentes externos, uma apresentação, a lista das abreviações e um guia da pronúncia italiana. Pela comparação com outros verbetes, acredita-se que o símbolo $(\square)$ pode indicar as acepções. Portanto, volerci e cavarsela poderiam ser considerados, em Martins Fontes, como acepções dos verbos volere e cavare. ${ }^{10}$

Observa-se quea locução ci vuol altro che [é preciso mais do que] que, na verdade, seria apenas mais um exemplo de uso do verbo volerci, é apresentada também como acepção, indicada pelo símbolo ( $\square$ ). Essa locução, ci vuol altro che, apresenta três equivalentes e três exemplos traduzidos.Todos os exemplos do verbete são traduzidos e conjugados, sendo

${ }^{10}$ Em relação aos VPs volerci e cavarsela no dicionário Martins Fontes, deduzimos que o símbolo ( $\square$ ) pode representar diferentes acepções dos verbos base. Entretanto, não há uniformidade de uso desse símbolo, já que o encontramos indicando também equivalentes em português em outros verbetes desse dicionário. 
SANTOS, R. D. DOS; BACCIN, P. G. - Dois verbos e duas medidas: comparando tratamentos lexicográficos de verbi procomplementari e phrasal verbs em dicionários bilíngues

que um está no passado. Há presença da forma plural, ci vogliono, em um dos exemplos.

Cavarsela é apresentado como verbo pronominal, o que não ocorre com volerci. Há um único exemplo, conjugado e traduzido (con quel lavoro me la cavo), mas parece estar deslocado em relação ao equivalente ao qual faz menção (virar-se), pois é apresentado após a locução cavarsela bene/male e não logo após a relação de equivalentes (escapar com vida, virar-se, sair-se bem, safar-se).

\section{cavare, v.tr. tirar, arrancar, sacar, extrair: cavare un ar- busto dal terreno, arrancar um arbusto; cavare un den- te, extrair um dente. $\square$ ganhar, obter, auferir, inferir, tirar: da tutto questo lavoro ci caverò ben poco, vou ganhar bem pouco com todo esse trabalho; cavare le conclusioni, tirar conclusões. $\mathbf{v}$ v.pr. tirar: cavarsi il cappello, tirar o chapéu. $\square$ (fig.) cavarsi la sete col prosciutto, ser pior a emenda que o soneto; cavarsi una voglia, satisfazer um desejo; cavarsi uno di tra i piedi, livrar-se de alguém; cavare sangue da una rapa, tirar leite de pedra. $\square$ cavarsela, escapar com vida; virar-se, sair-se bem; safar-se; cavarsela benel male, sair-se bem/mal; con quel lavoro me la cavo, com aquele trabalho me viro.}

Figura 1- Verbete cavare com o VP "cavarsela"- Dicionário Martins Fontes ItalianoPortuguês

\begin{tabular}{|l|c|c|}
\multicolumn{1}{c}{ Michaelis } & volerci & cavarsela \\
\hline Entrada & - & - \\
\hline Subentrada & $\mathrm{X}$ ? & X \\
\hline Definição & - & $\mathrm{X}(2)$ \\
\hline Equivalentes & $\mathrm{X}(1)$ & $\mathrm{X}(1)$ \\
\hline exemplo(s) & $\mathrm{X}(1)$ & \\
\hline
\end{tabular}


SANTOS, R. D. DOS; BACCIN, P. G. - Dois verbos e duas medidas: comparando tratamentos lexicográficos de verbi procomplementari e phrasal verbs em dicionários bilíngues

\begin{tabular}{|l|c|c|}
\hline Locuções & X (1) & - \\
\hline nota/marca de uso & - & $X$ (pop.) \\
\hline categoria gramatical & - & - \\
\hline Conjugação & - & - \\
\hline
\end{tabular}

4. Tabela: Presença dos VPs pesquisados no dicionário Michaelis

Neste dicionário, como no anterior, os VPs não são entrada, mas estão inseridos nos verbetes volere e cavare, respectivamente. 0 ponto de interrogação no quadro se refere a natureza do status de volerci dentro do verbete, já que seus significados estão presentes como uma quarta acepção de volere, com os equivalentes "ser necessário/ser preciso". A indicação da adição da partícula ci ocorre apenas no exemplo, deste modo, neste dicionário, torna-se mais complexo compreender que o significado dos equivalentes dados só ocorrerá com a união do verbo à partícula ci (que é obrigatória para a formação do sentido sintagmático), caracterizando, deste modo, uma falsa subentrada. Não há presença da forma plural (ci vogliono). É apresentada uma locução no condizionale (che ci vorrebbe a fare questo[o que custaria fazer isto?]), mas colocada separadamente e distante dos exemplos de volerci.

Neste dicionário, o VP cavarsela apresenta apenas dois equivalentes e um exemplo conjugado na terceira pessoa do singular e traduzido (se la cava bene da solo/ele se vira bem sozinho).

\begin{tabular}{|l|c|c|}
\multicolumn{1}{c}{ Parola Chiave } & volerci & cavarsela \\
\hline Entrada & - & - \\
\hline Subentrada & $\mathrm{X}$ & $\mathrm{X}$ \\
\hline Definição & $\mathrm{X}$ & $\mathrm{X}(1)$ \\
\hline Equivalentes & $\mathrm{X}(1)$ & - \\
\hline exemplo(s) & $\mathrm{X}(2)$ & - \\
\hline Locuções & - & $\mathrm{X}$ (símbolo/fig.) (pop.) \\
\hline nota/marca de uso & - & $\mathrm{X}$ \\
\hline categoria gramatical & - & \\
\hline Conjugação & - & \\
\hline
\end{tabular}

5. Tabela: Presença dos VPs pesquisados no dicionário Parola Chiave 
SANTOS, R. D. DOS; BACCIN, P. G. - Dois verbos e duas medidas: comparando tratamentos lexicográficos de verbi procomplementari e phrasal verbs em dicionários bilíngues

No dicionário Parola Chiave, os VPs também não são considerados como entrada. Observa-se a utilização da mesma simbologia empregada no dicionário Martins Fontes (por serem da mesma editora). 0 guia gráfico para consulta informa o significado de vários símbolos gráficos, como o trevo, os números, losangos etc., não indica, porém, a função do símbolo ( $\square)$. Pela análise dos verbetes, deduzimos que esse símbolo, no Parola Chiave, introduz os equivalentes em português. Apesar de ser o mesmo símbolo nos dois dicionários da editora Martins Fontes que analisamos, o significado não é uniformizado entre os dicionários e pode não ser universal dentro do mesmo dicionário, no caso do dicionário italiano-português da editora. 0 guia gráfico para consulta também informa que as formas pronominais do verbo estarão inseridas no verbete.

Neste terceiro dicionário, o VP volerci é indicado pelo número 6 , como uma acepção do verbo volere, seguido do símbolo (=), que introduz a definição em italiano (essere necessario, occorrere). Há dois exemplos no singular, mas não há presença da forma plural (civogliono), que é bastante relevante para o entendimento de que o VP é conjugado apenas na terceira pessoa do singular e na terceira pessoa do plural. Por fim, temos um equivalente em português (ser necessário).

O verbo cavarsela, é considerado como um sentido figurado do verbo cavare (assim como cavarsi), ambos indicados pelo símbolo do trevo e introduzidos pela barra vertical que indica locuções e modos de dizer. Assim como para o verbo volerci, também há a definição em italiano (superare senza gravi danni una situazione difficile), no entanto não há exemplos, somente um equivalente em português (safar-se).

A análise dos verbetes nos dicionários bilíngues inglês-português retornou os seguintes resultados: 
SANTOS, R. D. DOS; BACCIN, P. G. - Dois verbos e duas medidas: comparando tratamentos lexicográficos de verbi procomplementari e phrasal verbs em dicionários bilíngues

\begin{tabular}{|l|c|c|}
\multicolumn{1}{c}{ Michaelis } & give up & get over \\
\hline entrada & - & - \\
\hline subentrada & $\mathrm{X}$ & $\mathrm{X}$ \\
\hline definição & - & - \\
\hline equivalentes & $\mathrm{X}(3)$ & $\mathrm{X}(1)$ \\
\hline exemplo(s) & $\mathrm{X}(2)$ & $\mathrm{X}(1)$ \\
\hline locuções & $\mathrm{X}(2)$ & - \\
\hline nota/marca de uso & - & - \\
\hline categoria gramatical & - & - \\
\hline conjugação & - & - \\
\hline
\end{tabular}

6. Tabela: presença dos PhVs pesquisados no dicionário Michaelis

No dicionário Michaelis, os equivalentes de give upe de get oversão numerados, em negrito. As locuções dos PhVs estãoem negrito. Os exemplos são traduzidos. Os PhVs são listados ao final do verbete, mas sem a indicação de que se trata desta categoria gramatical. A conjugação é dada apenas no início do verbete, com a apresentação do particípio presente e passado do verbo base.

\begin{tabular}{|l|cc|}
\multicolumn{1}{c}{ Password } & give up & get over \\
\hline entrada & X & X \\
\hline subentrada & - & - \\
\hline definição & X & X \\
\hline equivalentes & X (6) & X (4) \\
\hline exemplo(s) & X (6) & X (4) \\
\hline locuções & - & - \\
\hline nota/marca de uso & - & - \\
\hline categoria gramatical & - & - \\
\hline conjugação & - & - \\
\hline
\end{tabular}

7. Tabela: Presença dos PhVs pesquisados no dicionário Password

Neste dicionário, são mostradas cinco acepções de give up e três acepções de get over. As acepções são numeradas, em negrito. Os exemplos estão em itálico e não são traduzidos. Os equivalentes também estão em negrito. Os PhVs ocupam a posição de uma entrada, mas não recebem o 
SANTOS, R. D. DOS; BACCIN, P. G. - Dois verbos e duas medidas: comparando tratamentos lexicográficos de verbi procomplementari e phrasal verbs em dicionários bilíngues

tratamento lexicográfico completo de uma entrada, isto é, não há indicação de categoria gramatical, pronúncia ou elementos relacionados à conjugação, que são fornecidos apenas em relação ao verbo base (give e get).

\begin{tabular}{|l|c|c|}
\hline \multicolumn{1}{|c|}{ Longman } & give up & get over \\
\hline Entrada & - & - \\
\hline subentrada & $\mathrm{X}$ & $\mathrm{X}$ \\
\hline definição & - & - \\
\hline equivalentes & $\mathrm{X}(2)$ & $\mathrm{X}(3)$ \\
\hline exemplo(s) & $\mathrm{X}(2)$ & - \\
\hline locuções & $\mathrm{X}(1)$ & - \\
\hline nota/marca de uso & - & - \\
\hline categoria gramatical & - & $\mathrm{X}$ \\
\hline conjugação & - & - \\
\hline
\end{tabular}

8. Tabela: Presença dos PhVs pesquisados no dicionário Longman

No dicionário Longman, a conjugação é dada apenas para o verbo base. A entrada (get e give) está em cor rosa e os PhVs em azul,apresentados como subentradas, mas em posição levemente recuada em relação à entrada, favorecendo a localização. Além disso, após as indicações gramaticais do verbo, consta a escrita "phrasal verbs", em negrito e versalete. Há a indicação da preposição a ser usada com o PhV, assim como a indicação de um complemento com pessoa ou com objeto. Os exemplos são traduzidos (para give up).

\section{Comparando e discutindo os dicionários e os tratamentos lexicográficos}


SANTOS, R. D. DOS; BACCIN, P. G. - Dois verbos e duas medidas: comparando tratamentos lexicográficos de verbi procomplementari e phrasal verbs em dicionários bilíngues

Facilmente constatável é o fato que, nos dicionários bilíngues pesquisados, nenhum dos VPs ou PhVs em análise é apresentado como entrada.

Nos dicionários Password e Longman do inglês, os PhVs se encontram em posições que proporcionam uma visualização mais rápida e fácil, que denominamos, para este trabalho, de "subentrada destacada". Não constituem entradas verdadeiras, uma vez que não recebem o tratamento lexical completo dado a outras entradas nos dois dicionários, tais como indicação de categoria gramatical e pronúncia, por exemplo.

No Longman, a subentrada destacada com os PhVs é apresentada em cor azul clara, em negrito, e levemente recuada em relação à entrada, que é apresentada em cor rosa, além de estarem elencados sob o título "phrasal verbs", em versalete. Esta é uma opção lexicográfica que se repete para todos os PhVs constantes do dicionário. No Password, a subentrada destacada dos PhVs também se apresenta em negrito, mas na cor preta, e também levemente recuada em relação ao verbo base. Esse posicionamento, em comparação com os VPs que se encontram colocados no interior do bloco único do verbo base italiano, promove a rápida identificação dos PhVs e das informações lexicográficas correspondentes a eles no dicionário. Outra opção lexicográfica adotada em relação aos PhVs é a numeração de suas diferentes acepções, seguidas pela definição em inglês (no caso do semibilíngue Password) e dos equivalentes, grafados em negrito no Password. No dicionário Michaelis, essas estratégias não são adotadas nem para o inglês, nem para o italiano.

No caso do Parola Chiave italiano, um dicionário semibilíngue como o Password inglês, o equivalente "ser necessário" em negrito se destaca mais do que o próprio volerci em itálico no dicionário, mas sem a subentrada destacada recuada, podendo induzir o consulente que faz uma consulta rápida ao verbete de que "ser necessário" pode ser equivalente de volere e não de 
SANTOS, R. D. DOS; BACCIN, P. G. - Dois verbos e duas medidas: comparando tratamentos lexicográficos de verbi procomplementari e phrasal verbs em dicionários bilíngues

volerci, semelhante à questão relacionada com o verbo volerci no Michaelis, apontada anteriormente.

No dicionário Michaelis, tanto os VPs quanto os PhVs se encontram ao final do verbete, em negrito, mas sem destaque de posição, inseridos no bloco do verbete. Tal fato confere, ao menos, coerência no tratamento lexical referente às duas tipologias verbais.

Uma das características norteadoras das opções lexicográficas adotadas para a elaboração de um dicionário é o público-alvo. Essa característica determinará escolhas referentes tanto à macro quanto à microestrutura do verbete. Nos dicionários analisados, apenas o da Martins Fontes italianoportuguês não tem os estudantes como público-alvo, mas na sua apresentação, alude aos tradutores e profissionais que lidam com a língua italiana profissionalmente. Muitas vezes, as necessidades em relação ao dicionário bilíngue são as mesmas para aprendizes, professores e tradutores, tais como o acesso rápido e direto à informação, a clareza da definição e a quantidade de equivalentes que deem conta de todas as acepções possíveis da unidade lexical buscada. Além disso, falando especialmente sobre aqueles que aprendem a língua italiana, há dois tipos de aprendizes, o aprendiz-usuário e o aprendiz-especialista:

Há dois tipos de aprendizes, os que desejam aprender a língua como usuários, apenaspara comunicar-se em italiano, e os que desejam aprender a língua como usuários, mas, também, com o objetivo de empregá-la como ferramenta de trabalho. Denominamos, portanto, aprendiz-especialista, o aluno que pretende usar o idioma como ferramenta de trabalho: o aluno que freqüenta os cursos de graduação em língua italiana nas Universidades brasileiras, cujo objetivo é tornar-se um profissional em língua italiana (bacharelado ou licenciatura). (BACCIN 2008:142)

De fato, é comum nas universidades brasileiras, principalmente no caso do italiano, o perfil do aprendiz-especialista, que tanto aprende o idioma quanto, concomitantemente, aprende a profissão de professor ou de tradutor, 
SANTOS, R. D. DOS; BACCIN, P. G. - Dois verbos e duas medidas: comparando tratamentos lexicográficos de verbi procomplementari e phrasal verbs em dicionários bilíngues

a qual se dedicará. Enquanto o aluno de inglês ingressa na universidade com algum conhecimento da língua, já que o vestibular prevê exames de língua inglesa para ingresso, o aluno de italiano não tem esse conhecimento prévio e, ao longo do curso, decidirá qual percurso profissional deseja seguir (licenciatura ou bacharelado).

Considerando-se os preceitos da lexicografia pedagógica bilíngue - na qual o público-alvo são os aprendizes de língua e o dicionário é construído com o intuito de fornecer ao aprendiz mais oportunidades de aprendizado, transformando o dicionário não apenas em um instrumento de consulta, mas também em um instrumento pedagógico adicional oferecido ao estudante as escolhas adotadas deveriam apresentar, de modo geral, características capazes de proporcionar aos consulentes informações mais claras e em maior quantidade sobre os PhVs e os VPs.

Segundo Hartmann e James (1998: 107), um dicionário pedagógico é "especificamente projetado para as necessidades didáticas práticas de professores e aprendizes de um idioma ${ }^{11}$." Dessa informação, é importante destacar que não somente os aprendizes de um idioma se beneficiam com determinadas escolhas lexicográficas, mas também o fato de que os professores podem encontrar respaldo e apoio didático para aprofundar e aprimorar a aprendizagem de estruturas consideradas mais complexas, como no caso dos PhVs e VPs.

Entretanto, há que se considerar as características do dicionário escolar e do dicionário para aprendizes, sempre levando em consideração os dois tipos de aprendizes apontados acima, o usuário e o especialista. O Longman traz na sua capa a afirmação de que é um dicionário escolar, "concebido para alunos do ensino médio no Brasil [...] e dotado de exemplos da língua escrita e falada relevantes para os adolescentes", segundo a sua introdução. Na capa

\footnotetext{
11 "[...] specifically designed for the practical didactic needs of teachers and learners of a language."
} 
SANTOS, R. D. DOS; BACCIN, P. G. - Dois verbos e duas medidas: comparando tratamentos lexicográficos de verbi procomplementari e phrasal verbs em dicionários bilíngues

do dicionário consta a informação "para estudantes brasileiros". No prefácio do Password, a primeira frase afirma que ele é "concebido especialmente para estudantes brasileiros", mas não especifica que tipo de estudantes, qual idade, de que tipo de escola ou curso ou com qual objetivo estudam outro idioma, levando-nos a pensar que talvez a designação correta para este caso seria "um dicionário para aprendizes" 12 .

Do mesmo modo, o dicionário Parola Chiave, que segue o modelo do Password para a língua italiana, também traz na sua apresentação que ele é um dicionário que "foi concebido especialmente para os estudantes brasileiros", sem deixar claro qual é o perfil dos estudantes do público-alvo.

Já o dicionário Martins Fontes, por ser o que tem o maior número de entradas em relação aos outros (poucos) bilíngues de língua italiana, é um dicionário bastante procurado por quem deseja se aprofundar no aprendizado da língua, independente do perfil que apresenta. Nesse sentido, mesmo um dicionário elaborado para "aqueles que lidam com a língua italiana em suas atividades profissionais", conforme a apresentação, beneficiaria o públicoalvo com soluções e opções mais pedagógicas, cobrindo o perfil do aprendizespecialista.

O Michaelis Dicionário Escolar Italiano diz na sua apresentação que "contém mais de $\mathbf{2 8 . 0 0 0 ~ v e r b e t e s ~ s e l e c i o n a d o s ~ e ~ a d a p t a d o s ~ p a r a ~ o s ~ b r a s i l e i r o s ~}$ que estudam a língua italiana e se preocupam em falar e escrevê-la corretamente". Apesar de ser intitulado como dicionário escolar, parece ser direcionado aos aprendizes de língua italiana, independentemente de ser um público de perfil escolar ou não.

\footnotetext{
${ }^{12}$ Apesar de seguirmos a classificação de Welker (2008: 27), na qual um dicionário escolar é somente monolíngue para falantes nativos, sabemos que muitos dicionários para aprendizes de uma língua estrangeira (LE) são assim denominados. De fato, Bugueño Miranda (2014: 221) afirma que "[...] a terminologia empregada para denominar muitos dicionários nem sempre contribui para obter clareza na tentativa de organizar um panorama das obras lexicográficas."
} 
SANTOS, R. D. DOS; BACCIN, P. G. - Dois verbos e duas medidas: comparando tratamentos lexicográficos de verbi procomplementari e phrasal verbs em dicionários bilíngues

Por fim, cabe analisar como as instruções de uso e as apresentações dos dicionários tratam os VPs e os PhVs.

Em relação aos componentes externos do dicionário, Al-Kasimi (1977: 109 apud WELKER 2008:283) reforça como uma das características de bons dicionários bilíngues (não necessariamente para aprendizes) a "existência de um guia que esclareça sobre os componentes do dicionário e as informações dadas (a estrutura dos verbetes, as convenções lexicográficas, por exemplo, as abreviaturas usadas e os símbolos fonéticos).

Ainda no Longman, na parte introdutória denominada "Como usar este dicionário - Guia rápido", é apresentado um infográfico no qual são indicados os "verbos com partículas", através de setas, os PhVs ligados à entrada (no caso, o verbo answer). A denominação "verbos com partículas" seria bastante apropriada para denominar, em português, os VPs italianos na introdução ou guia dos dicionários bilíngues, mas geralmente não há sequer menção à existência deles. No Parola Chiave há um "Guia gráfico para consulta", bastante semelhante ao guia do Longman, mas não há menção aos VPs e o guia é todo grafado em preto e branco, ao contrário do Longman, que é colorido. O Michaelis apresenta uma seção inicial com a "organização do dicionário" e "abreviaturas". No Martins Fontes italiano-português, há a "Lista das abreviações" e um "guia da pronúncia italiana", mas não há menção aos símbolos usados no dicionário, o que afeta os VPs aqui analisados, especialmente o VP volerci, que segue o símbolo (口), o mesmo usado para uma locução do verbo, como apontado anteriormente. Neste caso, não é possível saber, com certeza, a que o símbolo se refere nem porque é usado o mesmo símbolo para o verbo e para a locução. 
SANTOS, R. D. DOS; BACCIN, P. G. - Dois verbos e duas medidas: comparando tratamentos lexicográficos de verbi procomplementari e phrasal verbs em dicionários bilíngues

\section{Considerações finais}

Alguns dicionários pedagógicos parecem considerar o estudante (e não o aprendiz) como público-alvo, mantendo o adolescente como usuário imaginário dos dicionários "escolares".

O aprendiz, entretanto, é um usuário de idade e perfil não definido, que não apenas aprende um idioma, mas que também pode estar aprendendo uma profissão: a de professor de idiomas e/ou de tradutor. Nesses dois últimos casos, muitos itens no dicionário são determinantes não apenas para o aprendizado do idioma, mas também para a rápida localização da unidade lexical buscada - fundamental para o tradutor - bem como para proporcionar um modo de pensar a LE e ensiná-la a seus (possíveis) futuros alunos. A velocidade e facilidade da consulta ao dicionário é fundamental tanto para manter o fluxo da atividade de tradução (no caso dos tradutores) ou da produção ou da compreensão escrita (no caso dos aprendizes), como para evitar o somatório das pequenas perdas de tempo (e frustração) ao não se encontrar a informação buscada em uma consulta rápida ao dicionário.

No caso dos verbi procomplementari da língua italiana, de modo geral o tratamento lexicográfico recebido nos dicionários analisados neste trabalho é mais reduzido, menos variado e apresentado de modo menos visível, se comparado ao tratamento dado aos verbos da categoria verbal semelhante na língua inglesa, os phrasal verbs.

Além disso, na língua italiana, que não tem tradição de ensino como LE nas escolas, o contato com o idioma se dá, muitas vezes, apenas na faculdade ou em cursos de idiomas, contexto no qual os aprendizes já são adultos. Quando ocorre no curso de graduação em Letras, o usuário é, ao mesmo tempo, um aprendiz do idioma e da profissão de professor ou de tradutor. Todas as escolhas lexicográficas para facilitar a compreensão, a rapidez no manuseio do dicionário e para proporcionar apoio pedagógico para o ensino e 
SANTOS, R. D. DOS; BACCIN, P. G. - Dois verbos e duas medidas: comparando tratamentos lexicográficos de verbi procomplementari e phrasal verbs em dicionários bilíngues

eficácia na tradução não são apenas bem-vindas, são necessárias para que o consulente mantenha o dicionário como um meio de consulta confiável e prático.

Nesse sentido e nessa situação específica, o público-alvo é o profissional que lida com a língua italiana, mas os papeis de profissional e aprendiz podem se sobrepor e se confundir.

Portanto, consideramos que os verbi procomplementari devem ser considerados como entrada ou subentrada destacada nas obras lexicográficas e receber o tratamento lexicográfico relativo, como a possibilidade de inserção das locuções dos VPs diretamente ligados a eles, e não confundidos com locuções do verbo base ou com os próprios VPs, além de terem as informações relativas a eles tratadas de forma homogênea e uniforme. 0 tratamento de entrada ou subentrada destacada é pertinente primeiramente porque a definição de tais verbos não é resultante da soma de suas partes e, em segundo lugar, porque essa apresentação facilita e agiliza a consulta por parte de usuários do público-alvo, seja ele o aprendiz ou o tradutor.

\section{Referências bibliográficas}

BACCIN, P. G. Do português ao italiano: reflexões para elaboração de um dicionário pedagógico voltado para a produção. Revista de Italianística, v. XVII, São Paulo, FFLCH-USP, pp. 137-152, 2008.

Bugueño MiRAnda, F. V. Da classificação de obras lexicográficas e seus problemas: proposta de uma taxonomia. Alfa: revista de linguística, v. 58 (UNESP Online), pp. 215-231, 2014.

De MaURo, T. Grande dizionario italiano dell'uso - GRADIT. Torino: UTET, 2000. T. Il dizionario della lingua italiana. Milano: Paravia, 2000.

HARTMANN, R. R. K.; JAMES, G. Dictionary of Lexicography. Londres: Routledge, 1998. 
SANTOS, R. D. DOS; BACCIN, P. G. - Dois verbos e duas medidas: comparando tratamentos lexicográficos de verbi procomplementari e phrasal verbs em dicionários bilíngues

SANTOS, R. D. E chi se ne frega? Análise, reflexões e propostas para o tratamento lexicográfico de verbos italianos conjugados com mais de uma partícula pronominal. 2011. 186 f. Dissertação (Mestrado em Letras/Italiano) FFLCH, Universidade de São Paulo, São Paulo, 2011. Disponível em: http://www.teses.usp.br/teses/disponiveis/8/8148/tde-20082011-174646/ptbr.php. Acesso em: 10 set. 2015.

SIMONE, R. Esistono verbi sintagmatici in italiano? Cuadernos de Filología Italiana (Servicio de Publicaciones UCM), n.3, Madrid, 1996, pp. 47-61. Disponível em: www.revistas.ucm.es/fll/11339527/articulos/CFIT9696110047A.PDF. Acesso em: 10 set. 2015.

VIVIANI, A. I verbi procomplementari tra grammatica e lessicografia. Studi di grammatica italiana, $\mathrm{n}^{\circ}$ 25, Firenze, Accademia della Crusca, pp. 255-331, 2006.

WELKER, H.A. Panorama geral da lexicografia pedagógica. Brasília: Thesaurus, 2008.

\section{Obras Lexicográficas consultadas:}

ABREU, R. C. M. Dicionário escolar inglês-português / português-inglês. Harlow: Longman, 2002.

BenedetTI, I. C. Dicionário Martins Fontes Italiano Português. São Paulo: Martins Fontes, 2004.

DASTOLI, C. A. Parola Chiave Dizionario di italiano per brasiliani. São Paulo: Giunti \& Martins Fontes, 2007.

Kenerman, L. Password English dictionary for speakers of Portuguese.São Paulo: Martins Fontes, 1998.

Polito, A. G. Dicionário Escolar Italiano Michaelis. São Paulo: Melhoramentos, 2007.

SILVA, I. T. A. Michaelis Dicionário Escolar Inglês e Português. São Paulo: Melhoramentos, 2007 